One question (p. 10) seems to be so apocryphal, that we nust give it in full. "What separates the two organs of the levator labii superioris oliqui nasi? - the angular vein and artery." Where did the worthy bearer of the name of the great Winslow learn this singular fact; or how learned he, that the arteries (p. 11) were very liable to suffer adhesive inflammation? An agreeable reflection for an hypocondriac to hear, some fine day, that he was "very liable" to have his aorta bunged up by adhesive inflammatim! But we should never have done, did we attempt to correct all the errors which are contained in this book, although the author, so far sensibly, has curtailed its dimensions to a watch-pocket size. To conclude, then, with a few blunders, which will satisfy even the most lenient of critics :-

The thorax and abdomen form one great cavity in the body. - (P. 2.)

The gustatory nerve enters the angular foramen of the lower jaw.-(P. 19.)

There are four ventricles in the brain, viz., two lateral, a middle, and an inferior one.-(P. 39.)

In scirrhus of the testicle, the tumour forms beneath the emulgent artery.-(Y.68.)

In dislocation of the thigh into the foranen ovale, the foot is generally turned " outwards and inwards."-(P. 72.) Why not turned inside out, which would have been twice as intelligible?

This will suffice. If the book be a "Guide to the College," it must be a guide to the back door, for by no other part will a candidate for the diploma make his exit, if he rely upon this work for instruction. If he succeed, then will we raise up our hands, and exclaim, with a melancholy sigh, "Facilis decensus Averni!"

\section{DEATH BY FALLING FROIT THE CLOUDS.}

THE following is an account of the postmortem examination of the body of Mr. Robert Cocking, aged sixty-one, who fell with a suicidal machine called a parachute, from the cord of a balloon which ascended from Vauxhall Gardens, on the 24th of July, 1837. The height which the balloon had reached when the parachute commenced its descent, is stated to have been
5000 feet. The instrument of death was simply a canvas toy, constructed in igno. norance, and used with the hardihood which might distinguish an unfortunate being who contemplated his own destruction by extraordinary and wonderexciting means, -an end which, without the motive, was more effectually attained, by the crushing of the parachute in the air as it dropped :-

" On the right side.-The second, third, fourth, and fifth ribs broken near their junction, with their cartilages. The second, fourth, tifth, and sixth broken also near their junction with the vertebræ. The second, fourth, fifth, and sixth ribs also broken at their greatest convexity.

"On the left side.-The second, third, fourth, and sixth ribs broken near their cartilages, and also near their angles.

"The clavicle on the right side fractured at the junction of the external with the middle third.

"The second lumbar vertebra fractured through its body; the transverse processes of several of the lumbar vertebræ broken.

" Comminuted fracture and separation of the bones of the pelvis at the sacro-iliac symphyses.

"The ossa nasi fractured.

"The right ankle dislocated inwards; the astragalus and os calcis fractured.

"The viscera of the head, chest, and ab. domen free from any morbid appearances.
"F. C. Finch,
"G. Macllwain,
"W. MavghaM,
"T. GREeNWOOD,
"W. Thoupson,

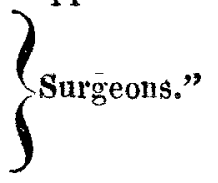

"AIr. Finch, and the other surgeons at the inquest, agreed in opinion as to the cause of the deceased's death, namely, the injuries he received in the concussion by the fall on the earth. The spinal marrow was likewise very greatly damaged. Mr. Finch also was of opinion, from the nature of some of the injuries, that the deceased had fallen on his feet. In addition to the ribs mentioned as haviug been broken, there was another, the eleventh rib on the left side, which by some mistake had been left out of the above paper. The hip-joint appeared not to have suffered any injury."

The Jury returned a verdict to this effect: - "We find that the deceased, Robert Cocking, came to his death casually, and by misfortune, in consequence of severe injuries received by a fall out of a parachute of his own invention and contrivance, which had been appended to a balloon; and we further find that the parachute did move to his death, and therefore that such parachute ought to become a deodand, and forfeited to the Queen." 